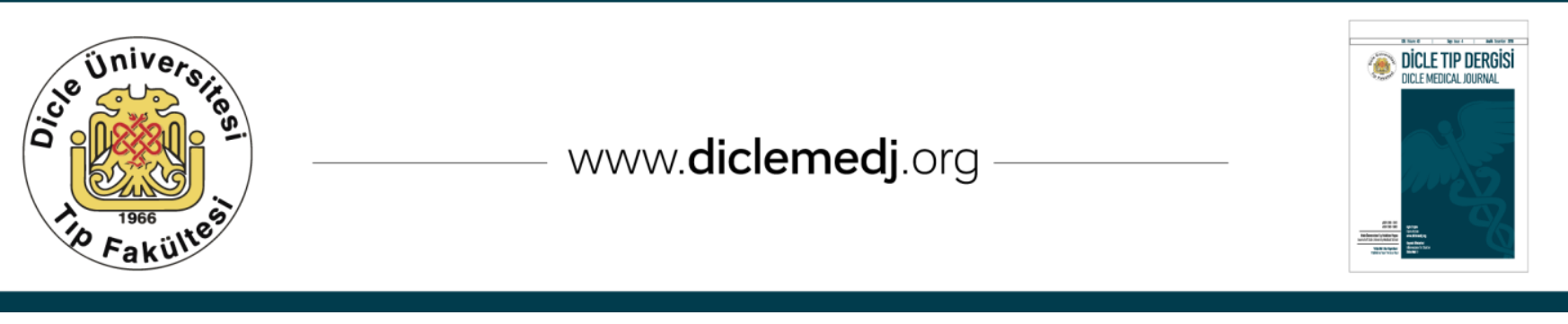

Olgu Sunumu / Case Report

\title{
Maligniteyi taklit eden pulmoner arteriyovenöz malformasyon: Olgu sunumu
}

\author{
Nilgün Yılmaz Demirci1', Nurettin Karaoğlanoğlu², Yurdanur Erdoğan³, \\ Ülkü Yılmaz ${ }^{3}$, Çiğdem Biber ${ }^{3}$
}

1 Gazi Üniversitesi, Tıp Fakültesi Göğüs Hastalıkları ABD, Ankara, Türkiye ORCID: 0000-0001-6160-3778

2 Yıldırım Beyazıt Üniversitesi, Göğüs Cerrahisi Kliniği, Ankara, Türkiye

3 Atatürk Göğüs Hastalıkları ve Gögüs Cerrahisi Eğitim Araştırma Hastanesi, Ankara, Türkiye

Geliş: 18.01.2017 Revizyon: 15.06.2017 Kabul Tarihi: 27.07.2017

Özet

Pulmoner arteriyovenöz malformasyonlar (PAVM) anormal kapiller gelişiminden kaynaklanan, çoğunlukla alt loblarda görülen konjenital lezyonlardır. Kırk iki yaşında kan tükürme yakınması olan olgu malignite ön tanısı ile kliniğimize refere edildi. Postero-anterior akciğer grafisinde sağda perihiler dansite artışı olması nedeni ile çekilen toraks bilgisayarlı tomografide (BT) sağ akciğer üst lobda lobüle konturlu kistik dansitede kitle lezyonu saptandı. Tanı ve evreleme amaçlı çekilen PET-BT'de sağ akciğer üst lobda $6.5 \times 5 \times 4.5 \mathrm{~cm}$ boyutunda kitlede minimal metabolik aktivite tutulumu (SUVmax:2.97) izlendi. Lezyondan sağ pulmoner vene uzanan, 5 mm'lik lümen kontrastlanması gösteren ve drenaj venine ait olabileceği düşünülen vasküler oluşum nedeniyle dev AVM olasılığı akılda tutulmalıdır şeklinde raporlandı. PAVM ön tanısı ile çekilen dinamik BT tromboze AVM olabileceği şeklinde değerlendirildi. Pulmoner anjiografide pulmoner arter ve dalları açı olarak izlendi. PAVM ve/veya arteriovenöz fistül izlenmedi. Tanısal amaçlı sağ torakotomi ile sağ üst lobektomi yapıldı. Postoperatif patolojisi PAVM ile uyumluydu. Olgumuzda üst lob tutulumu olması, pulmoner anjiografinin normal olması ve cerrahi ile tanı almış olması nedeni ile sunuldu.

Anahtar kelimeler: pulmoner arteriyovenöz malformasyon; malignite; anjiografi

DOI: $10.5798 /$ dicletip.339026

Yazışma Adresi / Correspondence: Nilgün Yılmaz Demirci, Gazi Üniversitesi, Tıp Fakültesi Göğüs Hastalıkları ABD, Ankara, Türkiye e-mail: nilgundemirci@gmail.com 


\title{
Pulmonary arteriovenous malformation mimicking malignancy: Case report
}

\begin{abstract}
Pulmonary arteriovenous malformations (AVM) are congenital lesions and are often arise in the lower lobes due to abnormal capillary development. Forty-two years old male patient presented with hemoptysis and he was referred to our clinic with the suspicion of malignancy.

Postero-anterior chest roentgenogram revealed homogenous opacity on the right perihilar zone. Computed tomography revealed a mass which was located at the right upper lobe. For the diagnosis and staging 18F-FDG PETCT was obtained. The mass was $6.5 \times 5 \times 4.5 \mathrm{~cm}$ and showed increased FDG uptake, 2,97. The lesion was considered as a large PAVM because of the linear density showing luminal contrast enhancement which was located between the lesion and right upper pulmonary vein. Dynamic contrast enhaced tomography revealed a solid mass with a suspicion of PAVM with thrombotic occlusion. Pulmonary angiography was free of AVM and fistulae. The patient underwent right upper lobectomy. Pathologic studies were consistent with pulmonary AVM. This case is presented because of upper lobe involvement, normal pulmonary angiography and the need of surgical operation as the only diagnostic tool.
\end{abstract}

Keywords: pulmonary arteriovenous malformation; malignancy; angiography

\section{GíRiş}

Pulmoner arteriyovenöz malformasyonlar (PAVM), sağ-sol şanta neden olabilen pulmoner arter ile pulmoner venler arasındaki anormal direkt bağlantılardır. Pulmoner damar yatağının en sık rastlanan anomalisidir. Tanıda pulmoner anjiografi altın standarttır. Genelde alt loblarda yerleşir. Radyolojik olarak 1-5 cm çapında, yuvarlak veya oval kitle/nodül opasitesi şeklinde olabilir. Bu yazıda üst lobda yerleşen, maligniteyi taklit eden, pulmoner anjiografisi normal olan ve cerrahi ile tanı alan PAVM olgusu literatür bilgileri eşliğinde sunulmuştur.

\section{OLGU}

Kırk iki yaşında erkek hasta, 10 gün önce başlayan kanlı balgam yakınması ile diş merkeze başvurmuş ve postero-anterior akciğer grafisinde (PA-AC) ve toraks bilgisayarlı tomografisi (BT)' nde akciğerde kitle izlenmesi üzerine akciğer kanseri ön tanısıyla hastanemize yönlendirilmiști. Kliniğimize yatışı esnasında hemoptizi yakınması devam ediyordu ve balgamla karışık yaklaşık 20-30 cc/gün idi. İnşaat işçisi olan olgumuz 7 yıl önce akciğer tüberkülozu geçirmişti ve 20 paket/yll sigara öyküsü mevcuttu, halen de içmekteydi. Olgumuzun soy geçmişinde özellik yoktu ve başvuru anında tüm sistem fizik muayenesi ve vital bulguları normaldi. Laboratuvar değerlerinde sedimantasyonun $45 \mathrm{~mm} / \mathrm{saat}$ olması dışında patoloji izlenmedi. Arteriyel kan gazında $\mathrm{pH}$ : 7.37, p02: $87 \mathrm{mmHg}$, pCO2: $38 \mathrm{mmHg}$ idi. Başvuru anındaki PA-AC grafisinde sağda orta alt zonda lobüle ve düzgün sınırlı dansite artışı izlendi (Resim 1). Toraks BT'de sağ akciğer üst lob anteriorda mediastinal ve kostal plevraya yaslanan lobüle konturlu çevresel ve internal kalsifikasyonlar içeren nodüler kitle lezyonu ve her iki akciğerde en büyüğü sol alt lob süperior segmentte $1 \mathrm{~cm}$ boyutlu olmak üzere dağınık yerleşimli nodüller, sol üst lob apikoposterior segmentte $1.5 \mathrm{~cm}$ boyutlu düzensiz konturlu nodül saptandı (Resim 2). Fiberoptik bronkoskopide endobronşiyal lezyon izlenmedi. Bronş lavajı sitolojisinde özellik yoktu ve asidorezistan basil negatifti. Transtorasik akciğer biyopsisi fibrin kitlesi olarak değerlendirildi. Akciğer kanseri ön tanısı ile çekilen Pozitron Emisyon Tomografi (PET) BT' de sağ akciğer üst lob anterior segmentte mediastinal ve kostal plevraya yaslanan, bilobüle görünümlü $6.5 \times 5 \times 4.5 \mathrm{~cm}$ boyutunda, $1.5 \times 1 \mathrm{~cm}$ boyutlarında periferik ve $9 \times 7 \mathrm{~mm}$ 
boyutlarında internal nodüler kalsifikasyon görünümleri içeren, minimal metabolik aktivite tutulumları (SUVmax:2.97) izlendi (Resim 3). Tarif edilen büyük lezyondan să̆ pulmoner vene uzanan, $5 \mathrm{~mm}$ çapında belirgin lümen kontrastlanması gösteren ve bu nedenle drenaj venine ait imaj görüntüsü veren vasküler oluşum nedeniyle dev AVM olabileceği belirtildi. PET-BT' de başka patolojik tutulum izlenmedi. AVM ön tanısı ile çekilen pulmoner anjiografide pulmoner arter ve dalları açık olarak izlendi. Pulmoner AVM ve/veya arteriovenöz fistül izlenmedi (Resim 4). Ekokardiyografisi normal olarak değerlendirildi. Pulmoner anjiografinin normal olması üzerine olguya tanı ve tedavi amaçlı torakotomi yapıldı. Sağ akciğer üst lobda $4 \times 6$ cm'lik palpabl kitle saptand. Kitleye ponksiyon yapılıp kavite açllarak hematom olduğu gözlendi. Makroskopik AVM düşünülen olguya üst lobektomi yapıldı. Postoperatif patolojisi de AVM ile uyumlu idi. Herhangi bir yakınması olmayan olgu daha sonra takibe alınd.

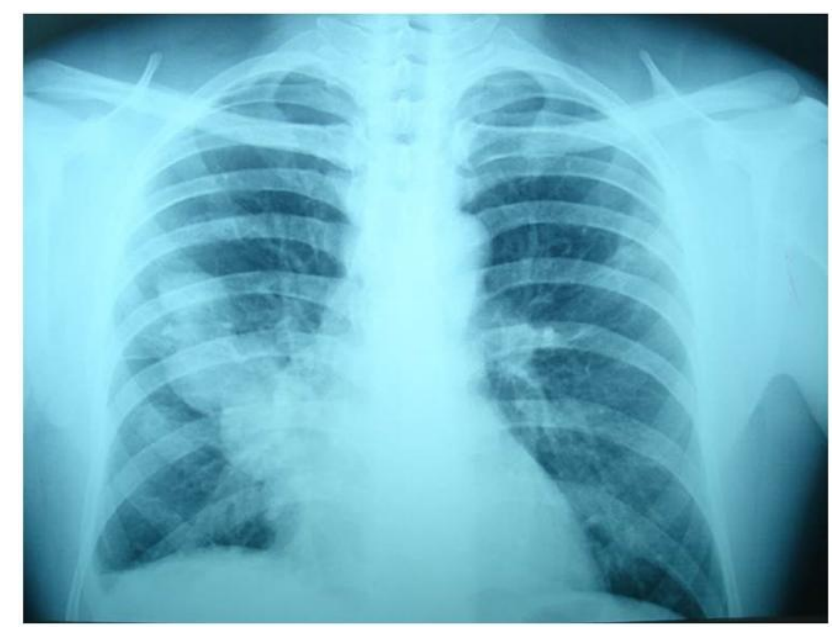

Resim 1. PA-AC grafisinde sağda orta alt zonda lobüle ve düzgün sınırlı dansite artışı izlenmektedir.

\section{TARTIŞMA}

Pulmoner arteriyovenöz malformasyonlar; pulmoner arteriyovenöz fistül, pulmoner arteriyovenöz anevrizma, pulmoner anjiyom, arteriyovenöz anjiyomatozis, kavernöz hemanjiyom olarak adlandırılmakla beraber, doğuştan ve malign potansiyeli olmayan lezyonlar oldukları için PAVM doğru tanımlamadır ${ }^{1}$. Kadınlarda erkeklerden iki kat daha fazla görülmektedir. Hayatın 3-4. dekatlarında görülür ${ }^{2}$. İzole anomali (\%40) olabileceği gibi herediter hemorajik telanjiektazi (HHT) sendromu ile birlikte (\%3088) de olabilir ${ }^{3}$. Bizim olgumuz 42 yaşında erkekti ve fizik muayenesi normaldi. Patogenezi tam olarak anlaşılamamakla beraber terminal arterlerde oluşan bir defekt ile ince duvarlı kapiller keselerinin dilatasyonu, fetal dönemde arteriyel ve venöz pleksusları ayıran septaların tam oluşmaması gibi mekanizmalar ileri sürülmektedir ${ }^{1}$. PAVM' ler yıllar içerisinde büyüme eğiliminde olup nadiren küçülürler. Hastaların \%13-55'i asemptomatiktir. Öksürük, nefes darlı̆̆l, hemoptizi, siyanoz, epistaksis ve şantlara bağlı semptomlarla da başvurabilir. Sağ-sol şantın derecesi klinik tabloyu etkilemektedir. Minimal şant varsa semptom yoktur veya subakut olarak bulunur. Sağ-sol şant sistemik kardiyak output'un $\% 20$ 'sinden fazlaysa veya redükte hemoglobin $5 \mathrm{gr} / \mathrm{L}$ 'den fazlaysa; siyanoz, çomak parmak ve polisitemi bu hastalarda görülebilir. $\mathrm{Bu}$ hastalarda periferik oksijen satürasyonu düşük olup $\% 100$ oksijen verildiğinde düzelmemektedir. Epistaksis, melena ve nörolojik semptomları bulunan hastalar HHT yönünden ayrıca incelenmelidir. Hemoptizi, intrabronşiyal rüptür sonrası olabilir. Semptomların varlığı AVM' nin boyutu ile ilişkili olup $<2 \mathrm{~cm}$ ise çoğu zaman semptom vermeyebilir. Hastaların \%75'inde muayene bulgusu olmayabilir. En sık siyanoz, çomak parmak ve pulmoner vasküler üfürüm saptanır. Ayrıca HHT' li olgularda ciltte telanjiektaziler görülür. Santral sinir sistemi ile ilişkili olarak bildirilen komplikasyonlar \%19 ila \%59 arasında olup migren, geçici iskemik ataklar, felç, serebral abseler en çok bildirilenlerdir ${ }^{1}$. Olgumuzun da başvuru yakınması kanlı balgam idi ve tüm sistem muayeneleri doğaldı. 

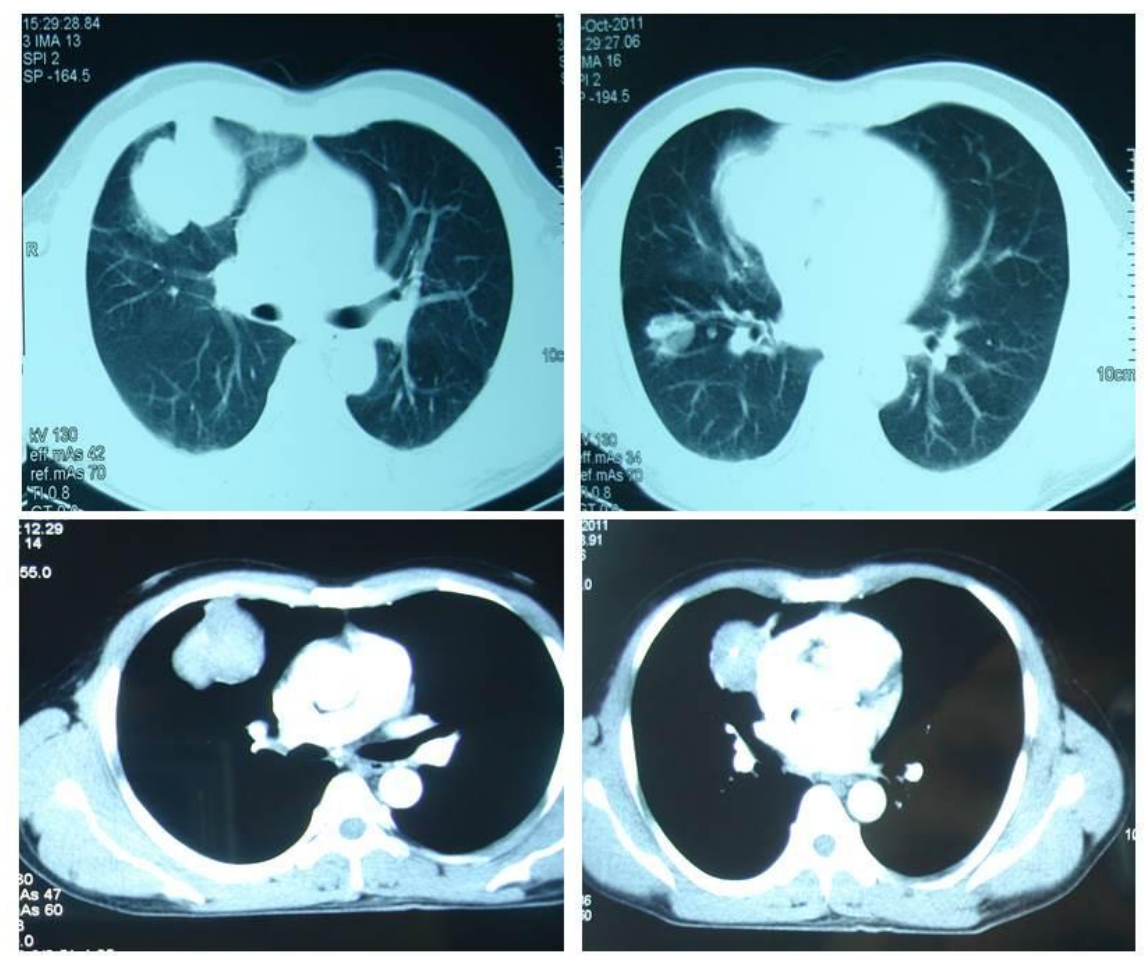

Resim 2. Toraks BT' de sağ akciğer üst lob anteriorda mediastinal ve kostal plevraya yaslanan lobüle konturlu çevresel ve internal kalsifikasyonlar içeren nodüler kitle lezyonu izlenmektedir

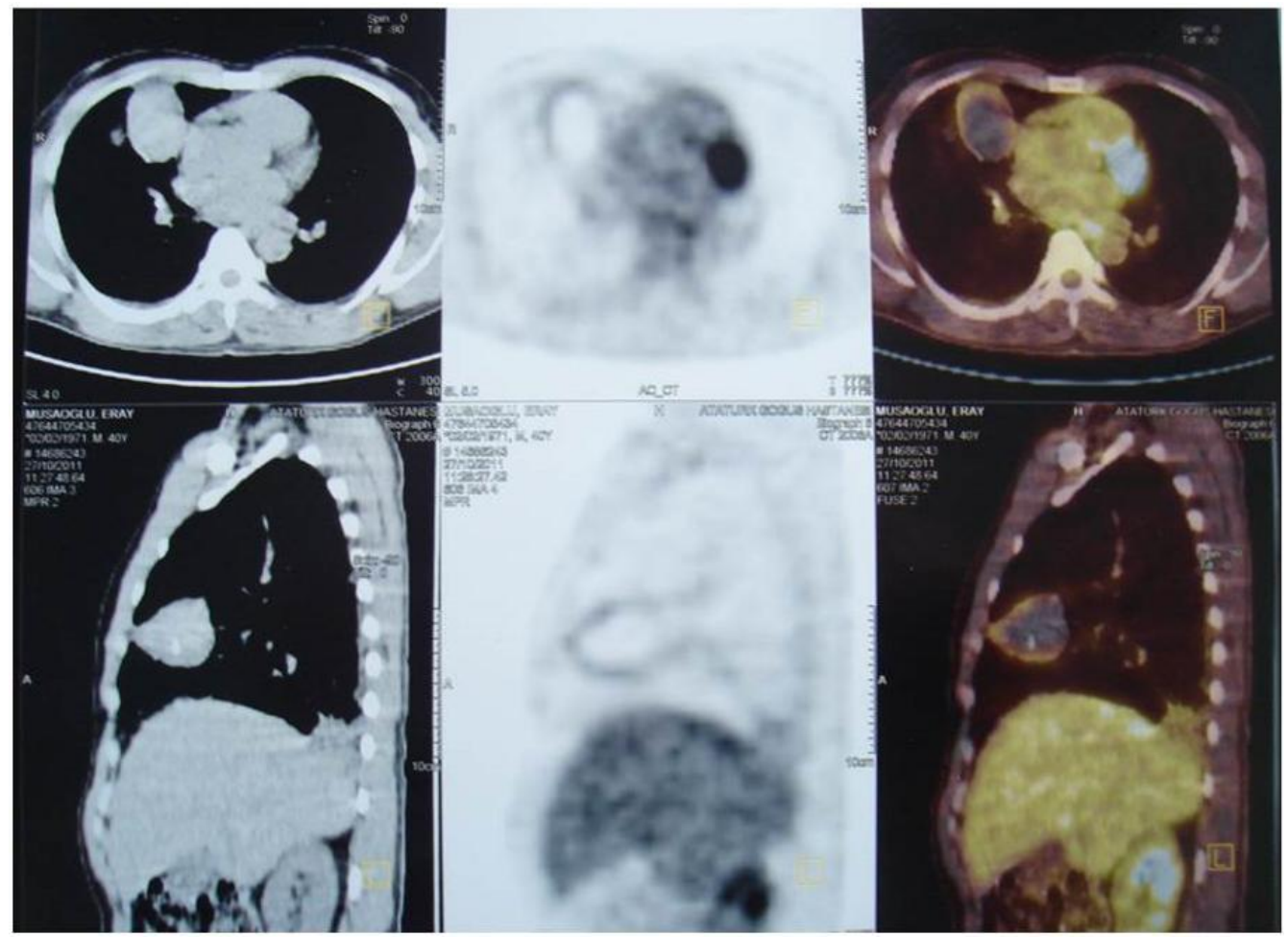

Resim 3. PET-BT' de sağ akciğer üst lob anterior segmentte, bilobüle görünümlü $6.5 \times 5 \times 4.5 \mathrm{~cm}$ minimal metabolik aktivite tutulumları (SUVmax:2.97) izlenmektedir 


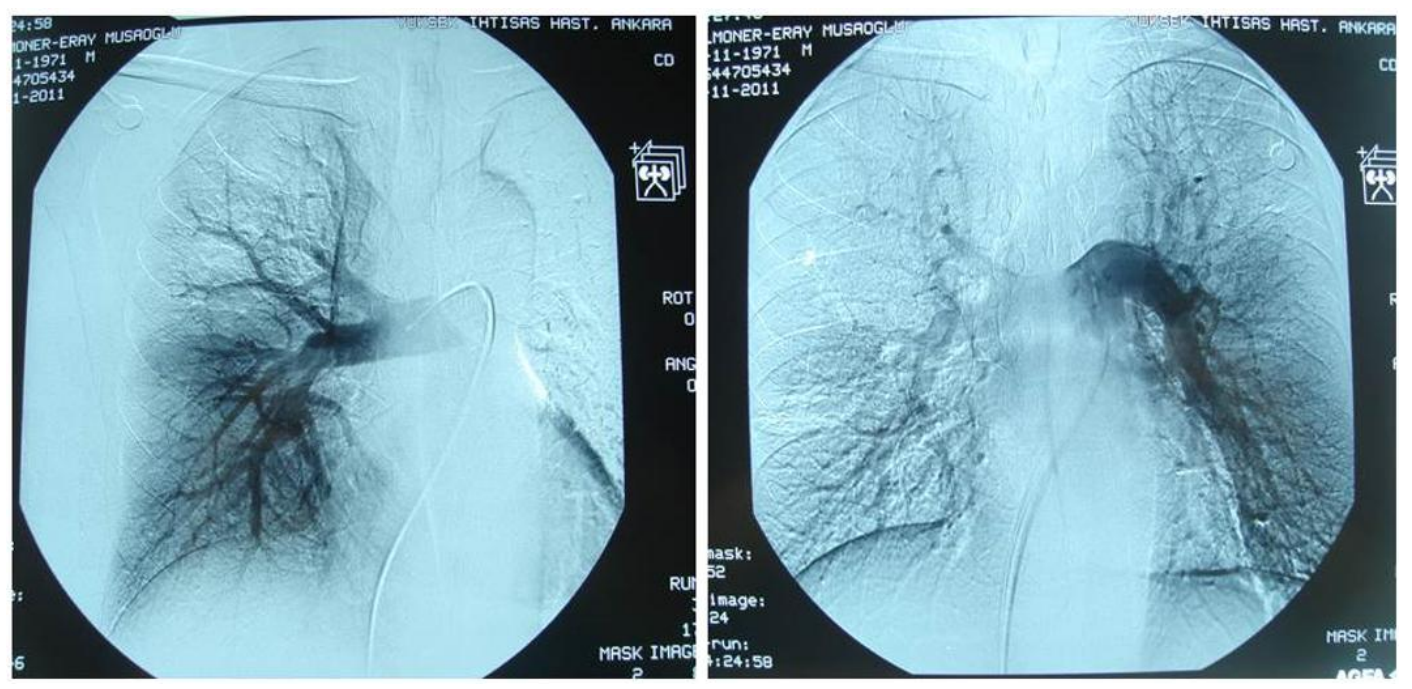

Resim 4. Pulmoner anjiyografide arteriyovenöz malformasyon izlenmedi.

PAVM' lar \%60-70 tek olabilir ve siklıkla alt loblardadır. \%30-40 çok sayıda olabilir ve yine alt loblarda sık görülür. Olguların \%80'inde plevral yüzeye yakın olarak yerleștiği görülmüştür. Boyut olarak çapları 1-5 cm arasında olup nadiren $10 \mathrm{~cm}$ 'ye ulaşabilir ${ }^{4}$. Olgumuzun lezyonları çok sayıda ancak üst loblardaydı ve plevral yüzeye yakındı. PAVM' ların \%79 oranında besleyici arteri ve boşaltıcı veni tek olup basit tiptedir, \%21' inde ise birden fazla besleyici arter ve boşaltıcı ven vardır ve kompleks tiptedir ${ }^{5}$.

Tanıda pulmoner anjiyografi ve manyetik rezonans anjiyografi, kontrastlı ekokardiyografi kullanılabilir. Altın standart pulmoner anjiografidir ${ }^{1}$. Hematomun okluziv basincl, hematomun veya posthemorajik ödemin kompresyonuna bağlı trombüs, vasküler spazm, damar duvarındaki regresif değişiklikler veya nidus kalsifikasyonu gibi çeşitli nedenlerle pulmoner anjiografi normal izlenebilir ${ }^{6}$ Olgumuzun pulmoner anjiografisinin normal olmasının bu nedenlerle ilişkili olabileceği düşünülmüștür.

PAVM' lu her olguda tedavi endikasyonu yoktur. Bir veya dahafazla besleyici arter çapı 2-3 mm'den büyük PAVM var ise embolizasyon önerilir. Bu sayede komplikasyonlar önlenmiş olur. Embolizasyon başarısız olursa veya rekanalizasyon gelişirse embolizasyon tekrarlanabilir. Başarısız embolizasyonlarda, ciddi kanama olanlarda, plevral boşluğa rüptüre olanlarda, kontrast madde allerjisi olanlarda ve lezyonu emboloterapi için uygun olmayanlarda cerrahi tedavi endikasyonu vardir7.

Olgumuzda üst lob tutulumu olması, pulmoner anjiografinin normal olması ve cerrahi ile tanı almış olması nedeni ile sunulmuştur.

Çıkar Çatışması Beyanı: Yazarlar çıkar çatışması olmadığını bildirmişlerdir.

Finansal Destek: Bu çalışma her hangi bir fon tarafından desteklenmemiştir.

Declaration of Conflicting Interests: The authors declare that they have no conflict of interest.

Financial Disclosure: No financial support was received. 


\section{KAYNAKLAR}

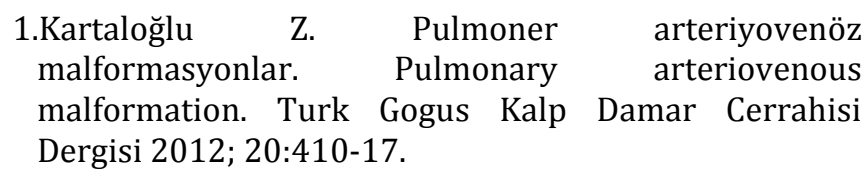

2. Van Gent MW, Post MC, Snijder RJ, et al. Real prevalence of pulmonary right-to-left shunt according to genotype in patients with hereditary hemorrhagic telangiectasia: a transthoracic contrast echocardiography study. Chest 2010;138:833-9.

3. Fuchizaki U, Miyamori H, Kitagawa S, et al. Hereditary haemorrhagic telangiectasia (Rendu-Osler-Weber disease) Lancet 2003;362:1490-4.

4. Kretschmar O, Ewert P, Yigitbasi $M$, et al. Huge pulmonary arteriovenous fistula: diagnosis and treatment and an unusual complication of embolization. Respir Care 2002;47:998-1001.
5. Wong HH, Chan RP, Klatt R, Faughnan ME. Idiopathic pulmonary arteriovenous malformations: clinical and imaging characteristics. Eur Respir J 2011;38:368-75.

6. Nawaz A, Litt HI, Stavropoulos SW, Charagundla SR, Shlansky-Goldberg RD, Freiman DB, Chittams J, Pyeritz RE, Trerotola SO. Digital subtraction pulmonary arteriography versus multidetector CT in the detection of pulmonary arteriovenous malformations. Vasc Interv Radiol. 2008;19:1582-8.

7. Kucukay F, Özdemir M, Şenol E, et al. Large pulmonary arteriovenous malformations: long-term results of embolization with Amplatzer vascular plugs. J Vasc Interv Radiol. 2014;25:1327-32. 